\title{
$\infty$
}

\section{A Comparative Analysis of Step and Touch Voltages Depending on Two Test Voltage Waveforms}

\author{
Kwang-Seok Jung, Sang-Wook Cha, Dae-Won Park, and Gyung-Suk Kil ${ }^{+}$ \\ Division of Electrical and Electronics Engineering, Korea Maritime University, Busan 606-791, Korea \\ Jae-Geun $\mathrm{Oh}^{+}$ \\ Division of Physics and Chemistry of Central District, National Forensic Service, Daejeon 305-348, Korea
}

Received March 2, 2011; Revised June 8, 2011; Accepted June 14, 2011

\begin{abstract}
This paper presents a comparative analysis on step and the touch voltages generated by either a sine and a ring wave voltage generator; this analysis was done as a basic study in order to develop a small and lightweight ground meter. A ring wave generator using pulsed power technology was fabricated; an experimental grounding system specified in Institute of Electrical and Electronics Engineers standards 80 and 81 was installed. The step and the touch voltages, which were measured using comparable a sine and a ring waves in terms of magnitude and frequency, were equal. Using pulsed power technology, the weight of the fabricated ring wave generator could be reduced to one-fifth of that of a sine wave generator. Consequently, if a ground meter adopts the ring wave instead of a sine wave, it will be possible to reduce the weight of a ground meter and improve the efficiency of measurement.
\end{abstract}

Keywords: Touch voltage, Step voltage, Ground meter, Ring wave generator, Pulsed power technology

\section{INTRODUCTION}

Grounding provides an electrical connection between electrical installations and the earth. The main functions of grounding is in preventing electric shocks to the human body and to protect electrical installations from a potential rise in current due to breakdown, lightning, or overvoltage by allowing the fault current to flow to the ground [1-4]. The performance of the grounding system, especially in regards to electric shock, is evaluated using step and the touch voltages.

Currently, the commercial frequency sine wave is used to measure the step and touch voltages. However, it requires a large approximately $40 \mathrm{~kg}$ transformer to make a few amperes of current to flow into the ground, which can cause difficulty in moving the

${ }^{\dagger}$ Author to whom all correspondence should be addressed: E-mail: kilgs@hhu.ac.kr

Copyright $\odot 2011$ KIEEME. All rights reserved.

This is an open-access article distributed under the terms of the Creative Commons Attribution Non-Commercial
License (http://creativecommons.org/licenses/by-nc/3.0) which permits unrestricted noncommercial use, distribution, and reproduction in any medium, provided the original work is properly cited. transformer to different sites [5-9].

As a solution to this problem, we fabricated a small and lightweight ring wave generator that uses pulsed power technology and carried out comparative analysis of the step and touch voltages upon the application of sine wave and ring wave voltages. The ring wave generator only consists of a high voltage circuit, a capacitor, and a non-saturation reactor, and therefore its weight can be reduced to one-fifth of that of the sine wave generator. An experimental grounding system was fabricated in accordance with Institute of Electrical and Electronics Engineers standards (IEEE Stds.) 80 and 81 in order to compare the step and the touch voltages on the basis of the test voltage waveforms $[10,11]$.

The results showed that the step and the touch voltages, which were compared using the sine and the ring wave in terms of equal magnitude and frequency, were the same. Additionally, it is possible to measure the step and the touch voltage using currents of different magnitudes at the same time if a ring wave is used.

\section{EXPERIMENTS}

A comparative analysis of the step and the touch voltage was 


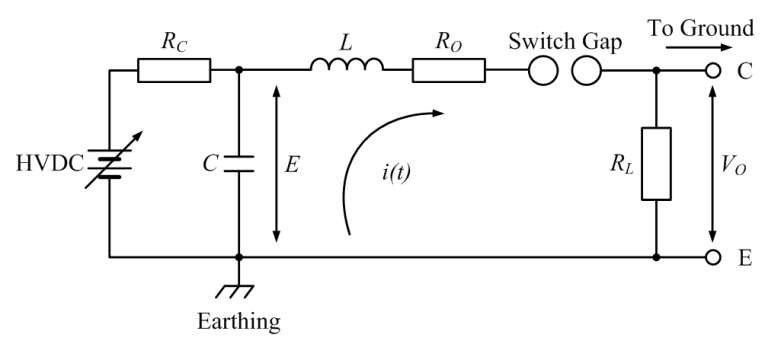

Fig. 1. The ring wave generator equivalent circuit.

(a)

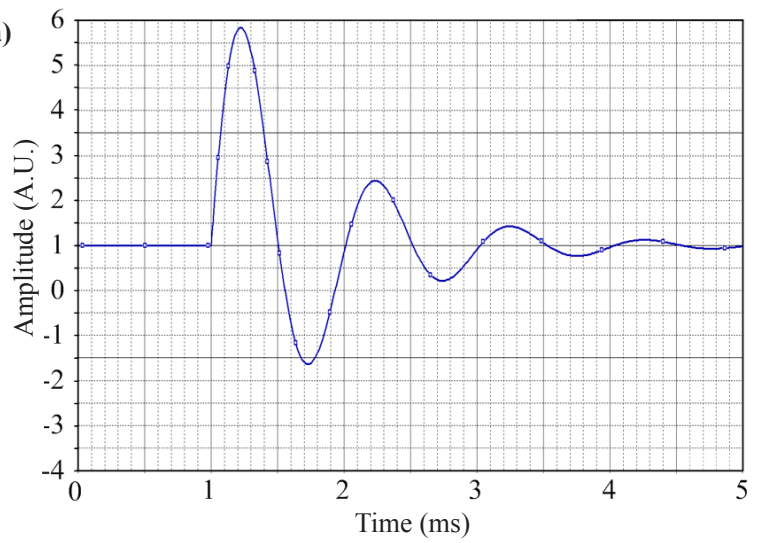

(b)

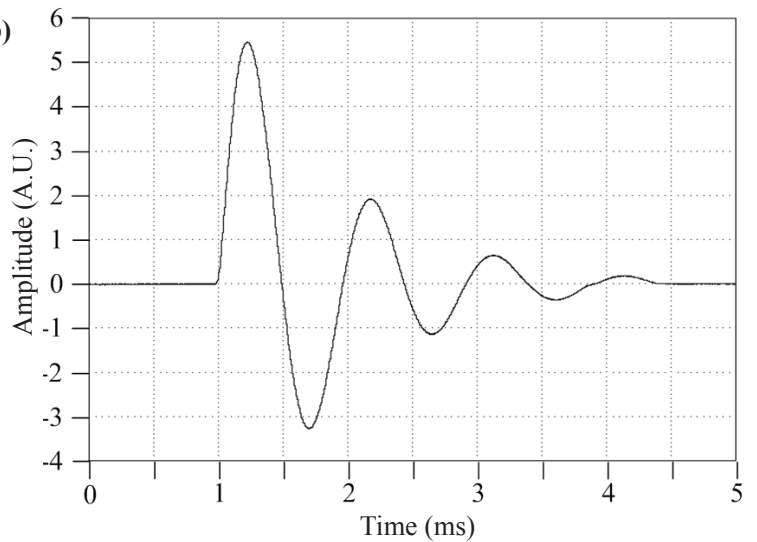

Fig. 2. The waveform comparison: (a) simulation and (b) generator.

carried out in a grounding system by applying a sine and a ring wave.

The sine wave was applied using a $300 \mathrm{~V}$ and $5.6 \mathrm{~A}$ inverter power supply which can vary its frequency over the range of 40 $\mathrm{Hz}-1 \mathrm{kHz}$. A ring wave was applied using the fabricated $300 \mathrm{~V}$ and $20 \mathrm{~A}$ pulsed power generator, which can adjust its frequency over the range of $100 \mathrm{~Hz}-1 \mathrm{kHz}$.

\subsection{Ring wave generator}

A ring wave generator consists of a high voltage DC supply (HVDC), a capacitor $(C)$, a charging resistor $\left(R_{C}\right)$, a non-saturation reactor $(L)$, and an output resistor $\left(R_{L}\right)$, as shown in Fig. 1.

The $C$ is charged up to $\mathrm{E}$ through the $R_{C}$. The $V_{O}$ is generated on both sides of $R_{L}$ when $C$ is discharged by closing the switch gap. The resistance of the switch gap shown in Fig. 1 is ignored, and so the basic equation can be expressed as [12]:

$$
L \frac{d i}{d t}+\left(R_{O}+R_{L}\right) i+\frac{1}{C} \int_{0}^{1} i d t=0
$$

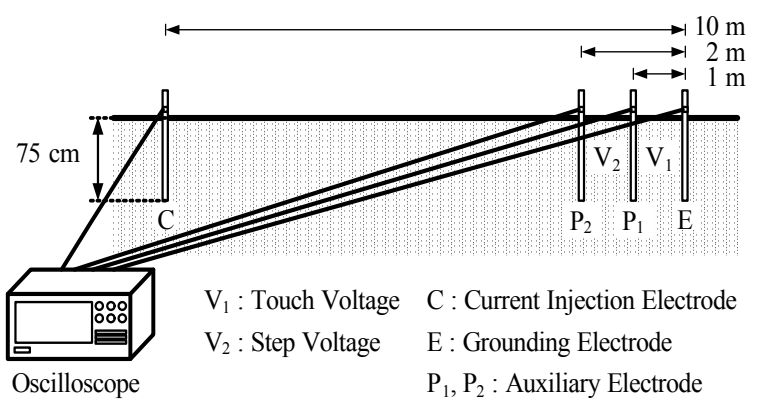

Fig. 3. The grounding system configuration.

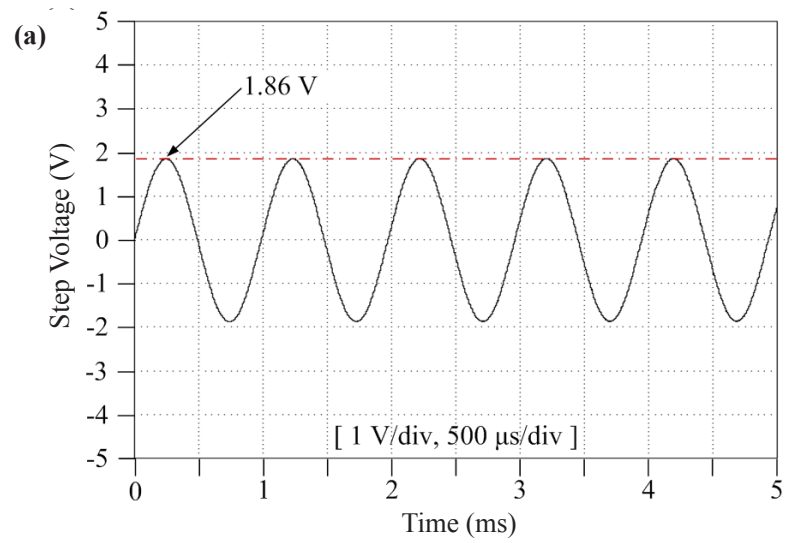

(b)

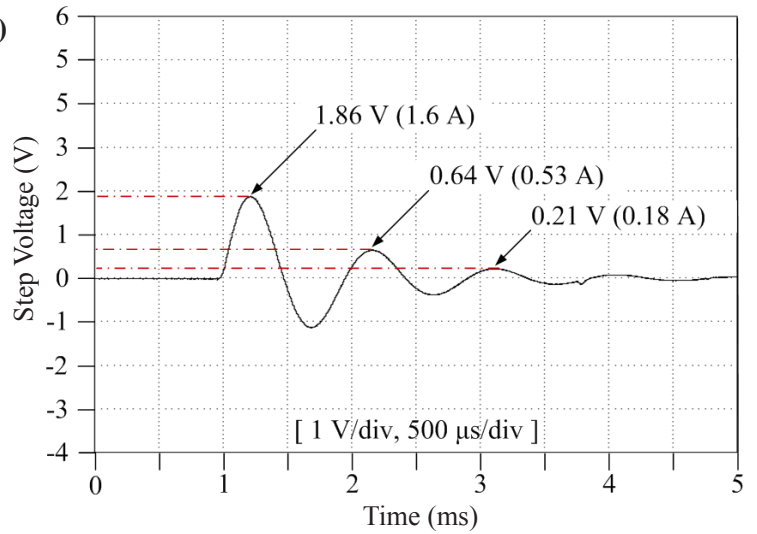

Fig. 4. The step voltage waveform comparison: (a) sine wave and (b) ring wave.

If the switch gap is closed at initial condition $t=0$, Eq. (1) can be solved for the following three conditions of $R\left(=R_{O}+R_{L}\right)$.

(a) When $R>2 \sqrt{L / C}$, the output voltage $V_{O}$ is a non-oscillation waveform which slowly attenuates after a fast rise; its solution is:

$V_{0}=i R_{L}=E \frac{R_{L}}{R} \bullet \frac{\alpha}{\beta}\left\{e^{(\alpha-\beta) t}-e^{(\alpha+\beta) t}\right\}$

(b) When $R=2 \sqrt{L / C}$, the output voltage $V_{O}$ is a critical damping waveform; its solution is:

$V_{0}=E \frac{R_{L}}{R} \bullet 2 \alpha \bullet e^{-\alpha t}$ 
(a)

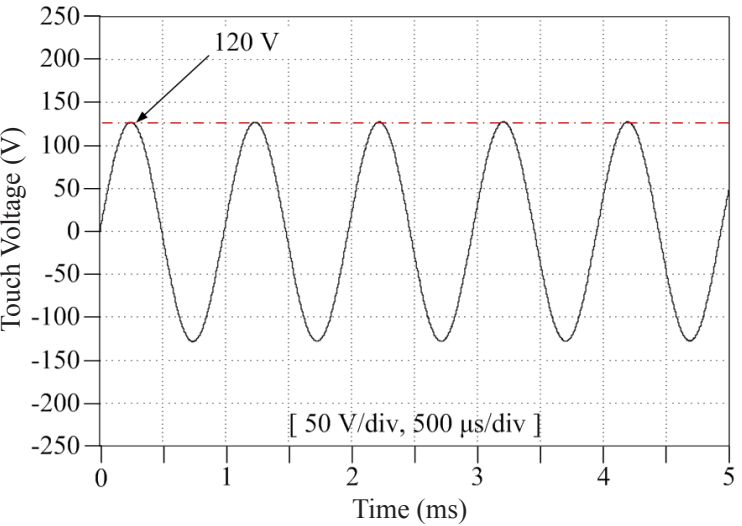

(b)

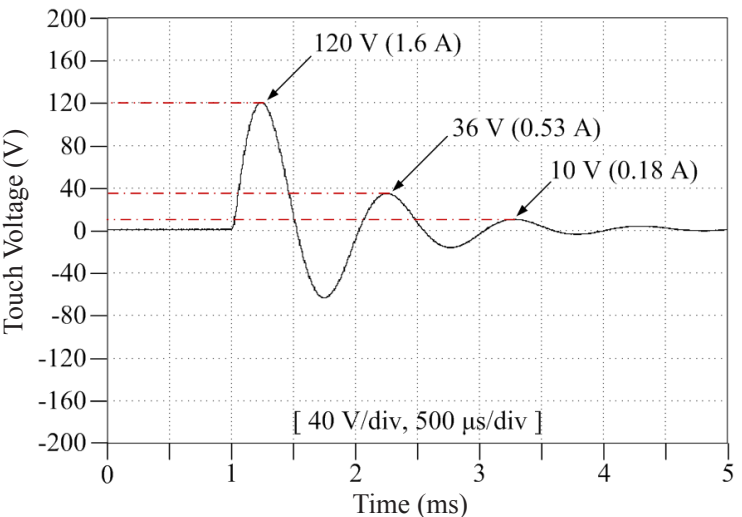

Fig. 5. The touch voltage waveform comparison: (a) sine wave and (b) ring wave.

(c) When $R<2 \sqrt{L / C}$, the output voltage $V_{O}$ is under a damping waveform; its solution is:

$$
\begin{aligned}
& V_{0}=E \frac{R_{L}}{R} \bullet 2 \frac{\alpha}{\omega} \bullet e^{-\alpha t} \sin \omega t \\
& \text { Here, } \alpha=\frac{R}{2 L}, \beta=\sqrt{\frac{R^{2}}{4 L^{2}}+\frac{1}{L C}}, \text { and } \omega=\sqrt{\frac{1}{L C}+\frac{R^{2}}{4 L^{2}}}
\end{aligned}
$$

A ring wave can be generated by decreasing $R$ and increasing $L$ as seen in Eq. (4); the frequency is set by the $R$ and $L$. A ring wave generator to measure the step and the touch voltages was designed through a simulation using PSpice and the above-stated theoretical analysis.

Figure 2 is an example of the output waveform from the fabricated ring wave generator. It shows that the waveforms from the generator and the simulation are almost equivalent.

\subsection{Grounding system}

A grounding system, shown in Fig. 3, was installed in accordance with IEEE Stds. 80 and 81 , used to compare the step and the touch voltage depending on test voltage waveforms, the sine and the ring wave. A grounding electrode (E) was buried $10 \mathrm{~m}$ away from a current electrode $(\mathrm{C})$ and potential electrodes $\left(\mathrm{P}_{1}\right.$, $\mathrm{P}_{2}$ ) were buried at $1 \mathrm{~m}$ distance from the grounding electrode.

After applying the ring and the sine wave voltage between the current electrode and the grounding electrode, the step and the touch voltage were calculated by measuring the voltage between E- $P_{1}\left(V_{1}\right)$ and $P_{1}-P_{2}\left(V_{2}\right)$ [11]. The current flowing to the grounding electrode was also measured.
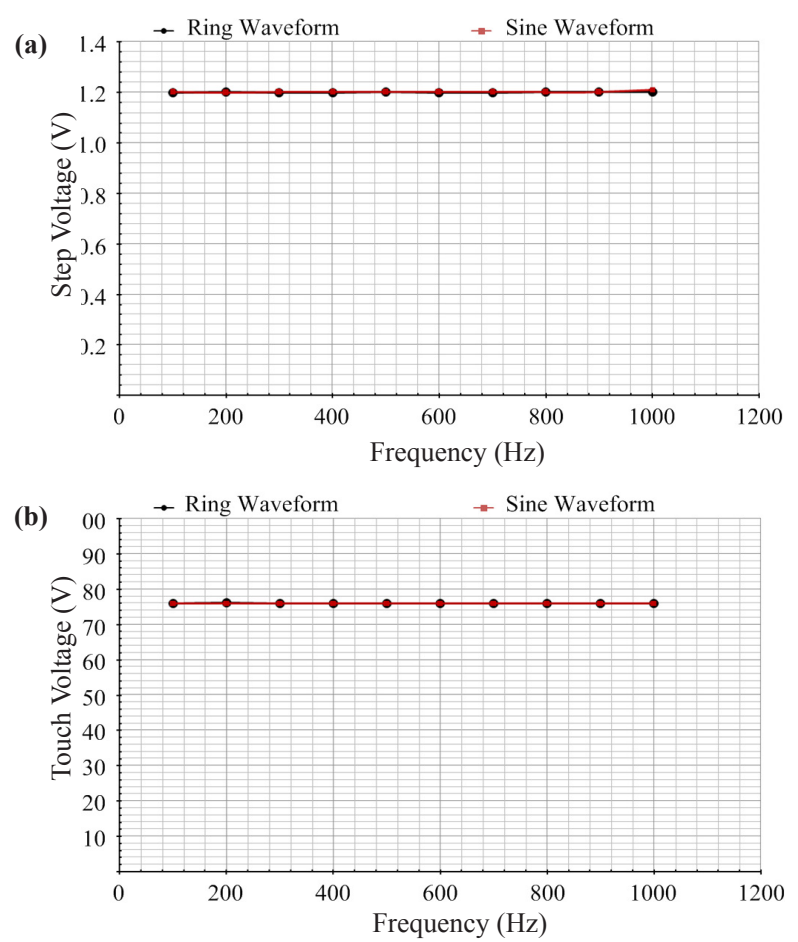

Fig. 6. The comparison between the step and the touch voltage depending on the frequency and waveform: (a) step voltage and (b) touch voltage.
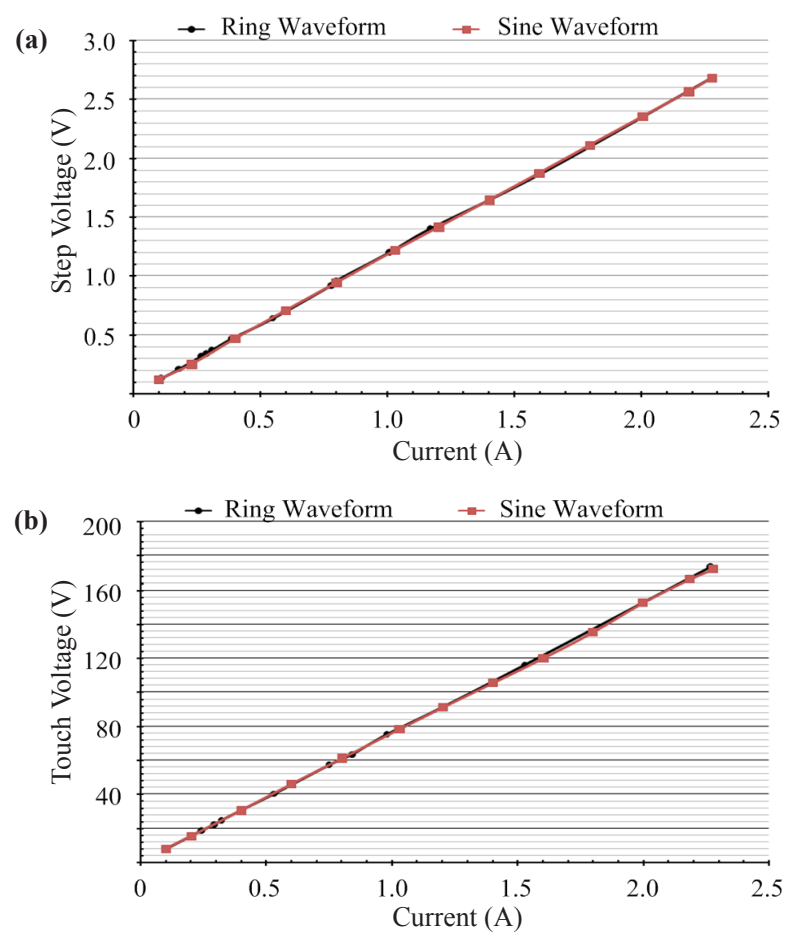

Fig. 7. The comparison between the step and the touch voltage depending on injected current: (a) step voltage and (b) touch voltage.

\section{RESULTS AND DISCUSSION}

Figures 4 and 5 show sample waveforms of the step and the touch voltages measured upon the application of sine and ring waves at $1.6 \mathrm{~A}$ and $1 \mathrm{kHz}$ to the grounding system. Provided that 
the sine and the first peak of the ring wave were $1.6 \mathrm{~A}$, the step voltage was consistently $1.86 \mathrm{~V}$.

As can be seen in Fig. 4(b), the step voltage at three magnitudes of current: $1.6 \mathrm{~A}, 0.53 \mathrm{~A}$, and $0.18 \mathrm{~A}$, can be measured at the same time when the ring wave is applied. The touch voltage was also equal to the sine and the ring wave, as shown in Fig. 5.

Figure 6 shows the comparison of the step and the touch voltage when the frequency of the test voltage is varied from $100 \mathrm{~Hz}$ to $1 \mathrm{kHz}$ with the current flowing at $1 \mathrm{~A}$. Regardless of the frequency or the test voltage waveform, the step voltage was $1.2 \mathrm{~V}$ and the touch voltage was $76 \mathrm{~V}$, showing equivalent results.

Figure 7 shows the comparison between the step and the touch voltages when the current flowing to the grounding electrode varies from $0.1 \mathrm{~A}$ to $2.3 \mathrm{~A}$ at a frequency of $1 \mathrm{kHz}$. The step and the touch voltages increase linearly in proportion to the applied current consistently for both waveform types.

In this paper, we carried out a comparative analysis on the step and the touch voltage of a grounding system depending on test voltage waveform at a current far smaller than an actual fault current. However, because an underground arc discharge may occur with a large fault current of several tens or hundreds of amperes flowing to the grounding systems, further studies regarding this phenomenon should be undertaken.

\section{CONCLUSIONS}

In order to develop a small and lightweight ground meter, we fabricated a ring wave generator and compared the step and the touch voltages of a grounding system when using sine and ring wave voltages. Using pulsed power technology, the weight of the fabricated ring wave generator can be reduced to one-fifth of that needed by a sine wave generator.

The experiment was performed on a grounding system specified in IEEE Stds. 80 and 81 . The results showed that the step and the touch voltages, which were measured under comparable sine and the ring wave voltages in terms of the magnitude $(0.1 \mathrm{~A}-2.3 \mathrm{~A})$ and the frequency $(100 \mathrm{~Hz}-1 \mathrm{kHz})$, were equal. Consequently, it is concluded that the weight of a ground meter can be reduced if the ring wave replaces the sine wave.

\section{ACKNOWLEDGMENTS}

This research was financially supported by the Ministry of Education, Science Technology (MEST) and the National Research Foundation of Korea (NRF) through the Human Resource Training Project for Regional Innovation and supported by the Electric Power Industry R\&D Program (R-2007-1-014-02) of Ministry of Knowledge Economy (MKE).

\section{REFERENCES}

[1] R. Morrison and W. H. Lewis, Grounding and Shielding in Facilities (Wiley, New York, 1990) p. 44-45.

[2] R. Kosztaluk, R. Mukhedkar, and Y. Gervais, IEEE Trans. Power App. Syst. PAS-103, 3286 (1984) [DOI: 10.1109/ TPAS.1984.318571].

[3] A. P. S. Meliopoulos, G. Cokkinides, H. Abdallah, S. Duong, and S. Patel, IEEE Trans. Power Del. 8, 1095 (1993) [DOI: $10.1109 / 61.252636]$.

[4] M. Khalifa, High-Voltage Engineering: Theory and Practice (Marcel Dekker, New York, 1990) p. 331-356.

[5] A. D. Papalexopoulos and A. P. Meliopoulos, IEEE Trans. Power Del. 2, 1073 (1987) [DOI: 10.1109/TPWRD.1987.4308223].

[6] A. P. S. Meliopoulos, Power System Grounding and Transients: An Introduction (Marcel Dekker, New York, 1988) p. 5-20.

[7] IEEE Std. 367-1996. IEEE Recommended Practice for Determining the Electric Power Station Ground Potential Rise and Induced Voltage From a Power Fault. p. 2 [DOI: 10.1109/ IEEESTD.1997.83838].

[8] A. Geri, IEEE Trans. Power Del. 14, 1008 (1999) [DOI: 10.1109 /61.772347].

[9] R. P. O'Riley, Electrical Grounding: Bringing Grounding Back to Earth, 6th ed. (Delmar Thomson Learning, Albany, NY, 2002) p. 40-43.

[10] IEEE Std. 80-2000. IEEE Guide for Safety in AC Substation Grounding. p. 114 [DOI: 10.1109/IEEESTD.2000.91902].

[11] IEEE Std. 81-1983. IEEE Guide for Measuring Earth Resistivity, Ground Impedance, and Earth Surface Potentials of a Ground System. p. 18-26 [DOI: 10.1109/IEEESTD.1983.82378].

[12] A. P. Meliopoulos and M. G. Moharam, IEEE Trans. Power App. Syst. PAS-102, 389 (1983) [DOI: 10.1109/TPAS.1983.317686]. 